\title{
PELABELAN PRIME CORDIAL PADA GRAF PRISMA DAN GRAF TERHUBUNG ANTAR PUSAT PADA GRAF RODA
}

\author{
Ismiyanti ${ }^{1}$, I W. Sudarsana ${ }^{2}$, S. Musdalifah ${ }^{3}$ \\ 1,2,3Program Studi Matematika Jurusan Matematika FMIPA Universitas Tadulako \\ Jalan Soekarno-Hatta Km. 09 Tondo, Palu 94118, Indonesia. \\ 1Aarkarnaafra@gmail.com, 2sudarsanaiwayan@yahoo.co.id, 3Selvymusdalifah@yahoo.com
}

\begin{abstract}
Prime Cordial Labeling on graph $\mathrm{G}$ is a bijective function $f: V(G) \rightarrow\{1,2,3, \ldots, p\}$ for every $e=u v$ such that $f(e)=$ 1 , if $\operatorname{gcd}(f(u), f(v))=1$ and 0 other wise, such that $\left|e_{f}(0)-e_{f}(1)\right| \leq 1$, where $e_{f}(0)$ is number of edge with label 0 and $e_{f}(1)$ is number of edge with label 1 . Prime cordial graph is a graph that can be labeled with prime cordial. In this paper we showed that $W_{n, t}$ for $t=\{2,4,6\}$ and $n \geq 3$ is a graph obtained by connecting each of the center of $t$ wheel on $\mathrm{n}+1$ vertices by an edge. We also proved that prism graph $P_{(n, m)}=C_{n} \mathrm{x} P_{m}$ is prime cordial with $n=3$ and $m \geq 5$ odd; $n=5$ and $m \geq 4$ even.
\end{abstract}

Key Words : Prime Cordial Labeling, Prism Graph, Wheel Graph

\section{ABSTRAK}

Pelabelan Prime cordial pada graf $\mathrm{G}$ adalah fungsi bijektif dari $f: V(G) \rightarrow\{1,2,3, \ldots, p\}$ untuk setiap $e=$ $u v$ sedemikian sehingga berlaku $f(e)=1$, jika $g c d(f(u), f(v))=1$ dan 0 jika lainnya, dan dipenuhi kondisi $\left|e_{f}(0)-e_{f}(1)\right| \leq 1$, dengan $e_{f}(0)$ adalah banyaknya sisi yang memperoleh label 0 dan $e_{f}(1)$ adalah banyaknya sisi yang memperoleh label 1. Sebuah graf yang memenuhi pelabelan prime cordial disebut graf prime cordial. Selanjutnya akan dilakukan penelitian pelabelan prime cordial pada graf terhubung antar pusat pada graf roda $W_{n, t}$ untuk $t \in\{2,4,6\}$ dan $n \geq 3$ dengan merumuskan pola label titik dan label sisinya pada graf tersebut. Selain itu, dilakukan pula penelitian pada graf prisma $P_{(n, m)}=C_{n} \times P_{m}$ untuk $n=3$ dan $m \geq 5$ ganjil, $n=5$ dan $m \geq 4$ genap.

Kata kunci : Graf Prisma, Graf Roda, Pelabelan Prime Cordial

\section{PENDAHULUAN}

Teori graf pertama kali diperkenalkan oleh Leonhard Euler pada tahun 1736 sebagai upaya pemecahan masalah jembatan Konigsberg. Masalah jembatan konigsberg adalah mungkin tidaknya melewati ketujuh jembatan yang ada dikota konigsberg masing - masing tepat satu kali dan kembali lagi ke tempat semula. Untuk memecahkan masalah tersebut, Euler mempresentasikan daratan 
yang dihubungkan jembatan dengan titik (vertex) dan jembatan dinyatakan dengan sisi (edge). Dengan menggunakan model tersebut, Euler berkesimpulan bahwa tidak mungkin seseorang dapat melalui ketujuh jembatan tersebut masing-masing satu kali dan kembali lagi ke tempat semula (Cunningham, 2004) [1].

Pelabelan merupakan pemetaan injektif yang memetakan unsur himpunan titik dan unsur himpunan sisi kebilangan asli yang disebut label. Pelabelan titik adalah pelabelan dengan domain himpunan titik, pelabelan sisi adalah pelabelan dengan domain himpunan sisi, dan pelabelan total adalah pelabelan dengan domain gabungan himpunan titik dan himpunan sisi (Erisia, 2011) [3].

Aplikasi pelabelan graf dapat dijumpai dalam berbagai bidang diantaranya desain sirkuit, dekomposisi graf, kriptografi, teori koding, radar (Munir, 2003) [5], desain jaringan komputer (Susmikanti, 2006) [6], ilmu kimia (Dubrov, 2000) [2] dan desain jaringan komunikasi (Kusumawardana, 2009) [4]. Ada banyak jenis pelabelan yang telah dikembangkan, salah satunya adalah pelabelan prima. Dalam pelabelan prima terdapat hubungan pada syarat pemadatan (fusion), duplikat (duplication), pertukaran titik (vertex switching), gabungan lintasan, dan penggabungan dua lintasan dari graf siklus. Pelabelan prime cordial pada graf $\mathrm{G}$ adalah fungsi Bijektif $f: V(G) \rightarrow$ $\{1,2,3, \ldots, p\}$ untuk setiap $e=u v \in E$ berlaku :

$$
\begin{aligned}
& f(e)=\left\{\begin{array}{l}
1, \text { jika } \operatorname{gcd}(f(u), f(v))=1 \\
0, \text { jika lainnya }
\end{array}\right. \\
& \left|e_{f}(0)-e_{f}(1)\right| \leq 1
\end{aligned}
$$

dengan $e_{f}(0)$ adalah banyaknya sisi yang diperoleh label 0 dan $e_{f}(1)$ adalah banyaknya sisi yang memperoleh label 1 .

\section{METODE PENELITIAN}

Berikut adalah penjelasan dari tahapan penelitian yang akan dilakukan penyusun dalam proses penelitian :

1. Memulai Penelitian.

2. Studi literatur.

3. Menotasikan titik dan sisi pada Graf Prisma $C_{n} \times P_{m}$ dan graf terhubung antara pusat dari graf roda $W_{n, t}$.

4. Memberikan label titik dan sisi pelabelan prime cordial pada Graf Prisma $C_{n} \times P_{m}$ dan graf terhubung antara pusat dari graf roda $W_{n, t}$.

5. Mendapatkan pola label titik pelabelan prime cordial pada Graf Prisma $C_{n} \times P_{m}$ dan graf terhubung antara pusat dari graf roda $W_{n, t}$.

6. Membangun teorema yang dilengkapi dengan bukti - bukti. 


\section{HASIL DAN PEMBAHASAN}

\subsection{HASIL}

Pada bab ini akan dibahas mengenai pelabelan Prime Cordial pada graf terhubung antar pusat dari graf roda $W_{n, t}$ dan graf Prisma $P_{(n, m)}=C_{n} \times P_{m}$. Untuk menunjukannya maka akan dilakukan langkah - langkah yaitu menotasikan titik dan sisi pada graf, pemberian label pada graf dan merumuskan pola titik dan sisi pada graf.

3.1.1. Pelabelan Prime Cordial pada Graf terhubung antar pusat pada Graf Roda $W_{n, t}$ Berikut akan dibahas mengenai pelabelan prime cordial pada graf terhubung antar pusat pada graf roda untuk $t$ genap.

a. Penotasian titik dan sisi secara umum Pada Graf terhubung antar Pusat pada Graf Roda $W_{n, t}$

Notasi titik dan sisi secara umum pada graf terhubung antar pusat pada graf roda $W_{n, t}$.dapat digambarkan sebagai berikut :

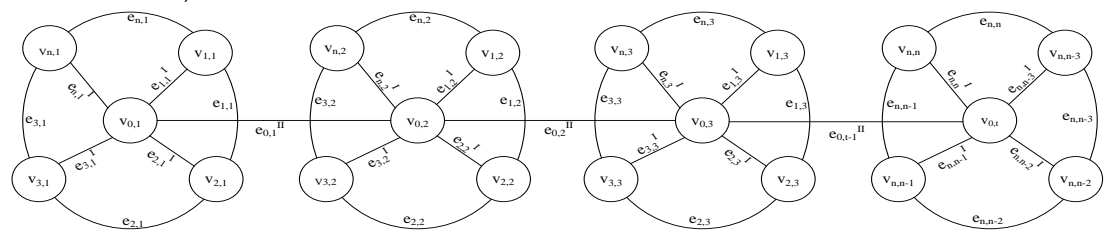

Gambar 1: Penotasian titik dan sisi pada graf terhubung antar pusat pada graf roda $W_{n, t}$

Berdasarkan gambar diatas, dapat dinotasikan graf terhubung antar pusat pada graf roda $W_{n, t}$ dengan himpunan titik dan sisi sebagai berikut :

$$
\begin{aligned}
& V\left(W_{n, t}\right)=\left\{v_{i, j}, v_{0, j} \mid 1 \leq i \leq n ; 1 \leq j \leq t\right\} \\
& E\left(W_{n, t}\right)=\left\{e_{i, j}, e^{\prime}{ }_{i, j}, e^{\prime \prime}{ }_{0, j} \mid 1 \leq i \leq n ; 1 \leq j \leq t-1\right\} \\
& \operatorname{dimana} \\
& e_{i, j}=v_{i, j} v_{i+1, j} ; 1 \leq i \leq n-1 \\
& e^{\prime}{ }_{i, j}=v_{0, j} v_{i, j} ; 1 \leq i \leq n 1 \leq j \leq t \\
& e^{\prime \prime}{ }_{0, j}=v_{0, j} v_{0, j+1} ; 1 \leq j \leq t-1
\end{aligned}
$$

b. Memberikan label titik dan sisi Pada Graf terhubung antar Pusat pada Graf Roda $W_{n, t}$. untuk $n \geq 3$ dan $t \geq 2$ genap

Berikut ini adalah graf roda dengan $n \geq 3$ dan $t \geq 2$ genap yang telah diperoleh dengan memeriksa himpunan titik $V$ fungsi bijeksi ke $\{1,2,3, \ldots,|V|\}$ 
pada graf dengan mencari greatest common divisor (gcd) dari $u v \in E$ dan telah diketahui memenuhi syarat prime cordialsebagai berikut :

- $\quad$ Kasus $\mathrm{n}=3$ dan $\mathrm{t}=2$

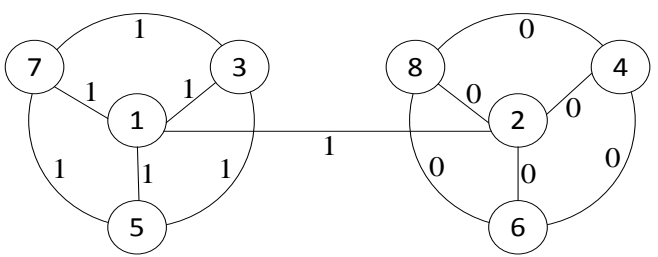

Gambar 2: Pelabelan Prime Cordia/ pada graf terhubung antar pusat pada graf roda $W_{3,2}$

Pada Gambar 2 graf terhubung antar pusat pada graf roda $W_{3,2}$ memiliki harga mutlak selisih dari banyak sisi yang berlabel 0 dan 1 adalah $\mid e_{f}(0)-$ $e_{f}(1)|=| 6-7|=|-1 \mid=1$. Dengan demikian graf terhubung antar pusat pada graf roda $W_{3,2}$ memenuhi syarat prime cordial.

- $\quad$ Kasus $\mathrm{n}=5$ dan $\mathrm{t}=4$

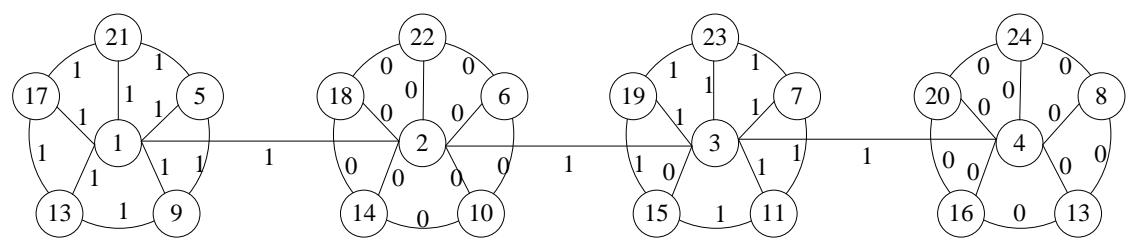

Gambar 3: Pelabelan Prime Cordialpada graf terhubung antar pusat pada graf roda $W_{5,4}$

Pada Gambar 3 graf terhubung antar pusat pada graf roda $W_{5,4}$ memiliki harga mutlak selisih dari banyak sisi yang berlabel 0 dan 1 adalah $\mid e_{f}(0)-$ $e_{f}(1)|=| 21-22|=|-1 \mid=1$. Dengan demikian graf terhubung antar pusat pada graf roda $W_{5,4}$ memenuhi syarat prime cordial.

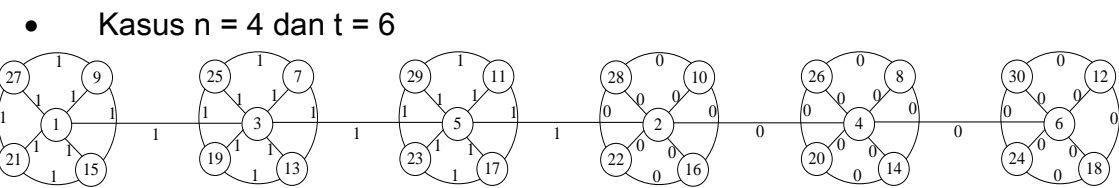

Gambar 4: Pelabelan Prime Cordia/ pada graf terhubung antar pusat pada graf roda $W_{4,6}$ 
Pada Gambar 4 graf terhubung antar pusat pada graf roda $W_{4,6}$ memiliki harga mutlak selisih dari banyak sisi yang berlabel 0 dan 1 adalah $\mid e_{f}(0)-$ $e_{f}(1)|=| 26-27|=|-1 \mid=1$. Dengan demikian graf terhubung antar pusat pada graf roda $W_{4,6}$ memenuhi syarat prime cordial.

C. Merumuskan pola label titik dan sisi Pada Graf terhubung antar Pusat pada Graf Roda $W_{n, t}$

Dari beberapa contoh graf dengan $t$ genap diatas, diperoleh hasil secara umum untuk graf terhubung antar pusat pada graf roda $W_{n, t}$ yang diformulasikan dalam teorema berikut :

\section{Teorema 1:}

Graf terhubung antar pusat pada graf roda $W_{n, t}$ adalah prime cordial untuk $n \geq$ 3 dan $t=2,4$.

Bukti : Kasus $n \geq 5$ dan $t=4$

Graf terhubung antar pusat pada graf roda $W_{n, 4}$ untuk $n \geq 5$ ditunjukan bahwa graf tersebut mempunyai pelabelan prime cordial dalam bentuk fungsi sebagai berikut :

$f\left(v_{i, j}\right)=t i+j, 1 \leq i \leq n ; 1 \leq j \leq t$

$f\left(v_{0, j}\right)=j, 1 \leq j \leq t$

dengan demikian diperoleh :

$f\left(e_{i, j}\right)=\left\{\begin{array}{l}1,1 \leq i \leq n ; 1 \leq j \leq t-3 \\ 0,1 \leq i \leq n ; 1 \leq j \leq t-2 \\ 1,1 \leq i \leq n ; 1 \leq j \leq t-1 \\ 0,1 \leq i \leq n ; 1 \leq j \leq t\end{array}\right.$

$f\left(e^{\prime}{ }_{i, j}\right)=\left\{\begin{array}{l}1,1 \leq i \leq n ; 1 \leq j \leq t-3 \\ 0,1 \leq i \leq n ; 1 \leq j \leq t-2 \\ 1,1 \leq i \leq 2 ; 1 \leq j \leq 2 \\ 0, i=3 ; j=3 \\ 0,1 \leq i \leq n ; 1 \leq j \leq t\end{array}\right.$

$f\left(e^{\prime \prime}{ }_{0, j}\right)=1,1 \leq j \leq t-1$ 
Berdasarkan fungsi tersebut diperoleh banyaknya sisi yang berlabel 0 adalah $e_{f}(0)=n-1$ dan banyaknya sisi yang berlabel 1 adalah $e_{f}(1)=n$. Sehingga $\left|e_{f}(0)-e_{f}(1)\right|=|(n-1)-n|=1$. Dengan demikian, fungsi pelabelan diatas adalah pelabelan prime cordial pada graf terhubung antar pusat pada graf roda $W_{n, 4}$ untuk $n \geq 5$. Jadi $W_{n, 4}$ adalah graf prime cordial.

\section{Teorema 2 :}

Graf terhubung antar pusat pada graf roda $W_{n, t}$ adalah prime cordial untuk $n \geq$ 3 dan $t=6$ genap

Bukti : Kasus $n \geq 4$ dan $t=6$

Graf terhubung antar pusat pada graf roda $W_{n, 6}$ untuk $n \geq 4$ ditunjukan bahwa graf tersebut mempunyai pelabelan prime cordial dalam bentuk fungsi sebagai berikut :

$$
f\left(v_{i, j}\right)=\left\{\begin{array}{l}
t i+3,1 \leq i \leq n ; j=1 \\
t i+1,1 \leq i \leq n ; j=2 \\
t i+5,1 \leq i \leq n ; j=3 \\
t i+4,1 \leq i \leq n ; j=4 \\
t i+2,1 \leq i \leq n ; j=5 \\
f\left(v_{0, j}\right)=\left\{\begin{array}{l}
j ; j=1,6 \\
2 j-1 ; j=2,3 \\
2 ; j=4
\end{array}\right. \\
4 ; j=5
\end{array}\right.
$$

dengan demikian diperoleh :

$$
\begin{aligned}
& f\left(e_{i, j}\right)=\left\{\begin{array}{l}
1,1 \leq i \leq n ; 1 \leq j \leq t-3 \\
0,1 \leq i \leq n ; t-2 \leq j \leq t
\end{array}\right. \\
& f\left(e^{\prime}{ }_{i, j}\right)=\left\{\begin{array}{l}
1 \leq i \leq n ; 1 \leq j \leq t-3 \\
0,1 \leq i \leq n ; t-2 \leq j \leq t
\end{array}\right. \\
& f\left(e^{\prime \prime}{ }_{0, j}\right)=\left\{\begin{array}{l}
1,1 \leq j \leq t-2 \\
0, t-1 \leq j \leq t
\end{array}\right.
\end{aligned}
$$

Berdasarkan fungsi tersebut diperoleh banyaknya sisi yang berlabel 0 adalah $e_{f}(0)=n-1$ dan banyaknya sisi yang berlabel 1 adalah $e_{f}(1)=n$. 
Sehingga $\left|e_{f}(0)-e_{f}(1)\right|=|(n-1)-n|=1$. Dengan demikian, fungsi pelabelan diatas adalah pelabelan prime cordial untuk graf terhubung antar pusat pada graf roda $W_{n, 6}$ untuk $n \geq 4$. Jadi $W_{n, 6}$ adalah graf prime cordial.

3.1.2. Pelabelan Prime Cordial Pada Graf Prisma $P_{(n, m)}=C_{n} \times P_{m}$

Berikut akan dibahas mengenai pelabelan prime cordial pada Graf Prisma $P_{(n, m)}=C_{n} \times P_{m}$.

a. Penotasian titik dan sisi secara umum Pada Graf Prisma $P_{(n, m)}=C_{n} \times P_{m}$

Notasi titik dan sisi secara umum pada graf Prisma $P_{(3, m)}=C_{3} \times P_{m}$ dapat digambarkan sebagai berikut :

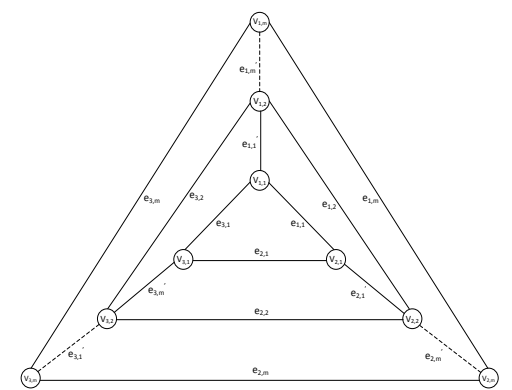

Gambar 5: Penotasian titik dan sisi pada graf Prisma $P_{(3, m)}=C_{3} \times P_{m}$

Berdasarkan gambar diatas, dapat dinotasikan graf Prisma $P_{(3, m)}=C_{3} \times$ $P_{m}$. dengan himpunan titik dan sisi sebagai berikut :

$$
\begin{aligned}
V\left(C_{3} \times P_{m}\right)= & \left\{v_{i, j} \mid 1 \leq i \leq 3 ; 1 \leq j \leq m\right\} \ldots \ldots \ldots \\
E\left(C_{3} \times P_{m}\right)= & \left\{e_{i, j}, e_{3, j} \mid 1 \leq i \leq 2 ; 1 \leq j \leq m\right\} . \\
& \left\{e^{\prime}{ }_{i, j} \mid 1 \leq i \leq 3 ; 1 \leq j \leq m-1\right\}
\end{aligned}
$$

dimana

$e_{i, j}=v_{i, j} v_{i+1, j} ; 1 \leq i \leq 2 ; 1 \leq i \leq m$

$e_{3, j}=v_{i, j} v_{3, j} ; 1 \leq i \leq 2 ; 1 \leq i \leq m$

$e^{\prime}{ }_{i, j}=v_{i, j} v_{i, j+1} ; 1 \leq i \leq 3 ; 1 \leq j \leq m-1$

Notasi titik dan sisi secara umum pada graf Prisma $P_{(5, m)}=C_{5} \times P_{m}$ dapat digambarkan sebagai berikut : 


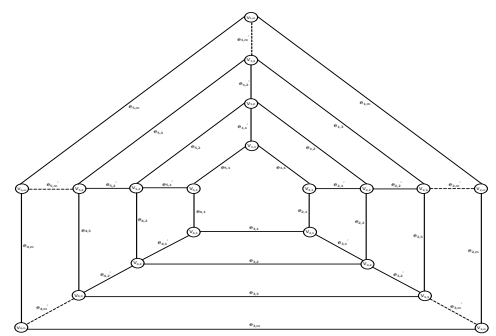

Gambar 6: Penotasian titik dan sisi pada graf Prisma $P_{(5, m)}=C_{5} \times P_{m}$

Berdasarkan gambar di atas, dapat dinotasikan graf Prisma $P_{(5, m)}=C_{5} \times P_{m}$. dengan himpunan titik dan sisi sebagai berikut :

$V\left(C_{5} \times P_{m}\right)=\left\{v_{i, j} \mid 1 \leq i \leq 5 ; 1 \leq j \leq m\right\}$

$E\left(C_{5} \times P_{m}\right)=\left\{e_{i, j}, e_{5, j} \mid 1 \leq i \leq 4 ; 1 \leq j \leq m\right\}$

$\left\{e^{\prime}{ }_{i, j} \mid 1 \leq i \leq 5 ; 1 \leq j \leq m-1\right\}$ dimana,

$e_{i, j}=v_{i, j} v_{i+1, j} ; 1 \leq i \leq 4 ; 1 \leq j \leq m$

$e_{5, j}=v_{i, j} v_{5, j} ; 1 \leq i \leq 4 ; 1 \leq j \leq m$

$e^{\prime}{ }_{i, j}=v_{i, j} v_{i, j+1} ; 1 \leq i \leq 5 ; 1 \leq j \leq m-1$

b. Memberikan label titik dan sisi Pada Graf Prisma $P_{(n, m)}=C_{n} \times P_{m}$

Berikut ini adalah graf Prisma $P_{(n, m)}=C_{n} \times P_{m}$ dengan $n \geq 3$ dan $m \geq 5$ ganjil yang telah diperoleh dengan memeriksa himpunan titik $V$ fungsi bijeksi ke $\{1,2,3, \ldots,|V|\}$ pada graf dengan mencari greatest common divisor (gcd) dari $u v \in E$ dan telah diketahui memenuhi syarat prime cordialsebagai berikut :

- $\quad$ Kasus $n=3$ dan $m=5$

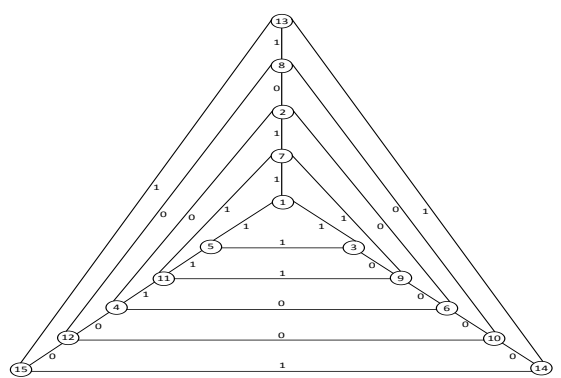

Gambar 7: Pelabelan Prime Cordia/ pada Graf Prisma $P_{(3,5)}$

Pada Gambar 7 Graf Prisma $P_{(3,5)}$ memiliki harga mutlak selisih dari banyak sisi yang berlabel 0 dan 1 adalah $\left|e_{f}(0)-e_{f}(1)\right|=|13-14|=|-1|=1$. Dengan demikian Graf Prisma $P_{(3,5)}$ memenuhi syarat prime cordial. 
- $\quad$ Kasus $n=5$ dan $m=4$

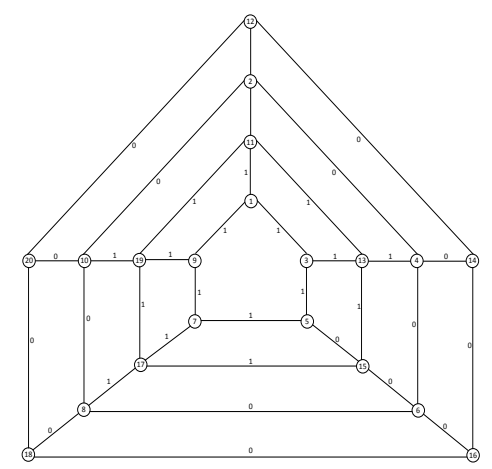

Gambar 8: Pelabelan Prime Cordial pada Graf Prisma $P_{(5,4)}$

Pada Gambar 8 Graf Prisma $P_{(5,4)}$ memiliki harga mutlak selisih dari banyak sisi yang berlabel 0 dan 1 adalah $\left|e_{f}(0)-e_{f}(1)\right|=|17-18|=|-1|=1$. Dengan demikian Graf Prisma $P_{(5,4)}$ memenuhi syarat prime cordial.

c. Merumuskan pola label titik dan sisi Pada Graf Prisma $P_{(n, m)}=C_{n} \times P_{m}$

Dari beberapa contoh graf dengan diatas, diperoleh hasil secara umum untuk Graf Prisma $P_{(n, m)}$ yang diformulasikan dalam teorema berikut :

\section{Teorema 3 :}

Graf Prisma $P_{(3, m)}$ adalah prime cordial untuk $n=3$ dan $m \geq 5$ ganjil

Bukti : Kasus $n=3$ dan $m \geq 5$ ganjil

Graf Prisma $P_{(3, m)}$ untuk $n=3$ dan $m \geq 5$ ganjil ditunjukan bahwa graf tersebut mempunyai pelabelan prime cordial dalam bentuk fungsi sebagai berikut :

$$
f\left(v_{i, j}\right)=\left\{\begin{array}{l}
2 i-j ; 1 \leq i \leq n, j=1 \\
2 i ; 1 \leq i \leq n, j=\left\lceil\frac{m}{2}\right\rceil+1 \\
1+(j-1) 6 ; i=1,2 \leq j \leq\left\lfloor\frac{m}{2}\right\rfloor \\
2+\left(j-1-\left\lceil\frac{m}{2}\right\rceil\right) 6 ; i=1,\left\lceil\frac{m}{2}\right\rceil+2 \leq j \leq m-1 \\
3+(j-1) 6 ; i=2,2 \leq j \leq\left\lfloor\frac{m}{2}\right\rfloor \\
4+\left(j-1-\left\lceil\frac{m}{2}\right\rceil\right) 6 ; i=2,\left\lceil\frac{m}{2}\right\rceil+2 \leq j \leq m-1 \\
5+(j-1) 6 ; i=3,2 \leq j \leq\left\lfloor\frac{m}{2}\right\rfloor \\
6+\left(j-1-\left\lceil\frac{m}{2}\right\rceil\right) 6 ; i=3,\left\lceil\frac{m}{2}\right\rceil+2 \leq j \leq m-1
\end{array}\right.
$$

dengan demikian diperoleh : 


$$
\begin{aligned}
& f\left(e_{i, j}\right)=\left\{\begin{array}{l}
1,1 \leq i \leq 2 ; 1 \leq j \leq\left\lfloor\frac{m}{2}\right\rfloor \\
0,1 \leq i \leq 2 ;\left\lfloor\frac{m}{2}\right\rfloor+1 \leq j \leq m-1
\end{array}\right. \\
& f\left(e_{3, j}\right)=\left\{\begin{array}{l}
1,1 \leq i \leq 2 ; 1 \leq j \leq\left\lfloor\frac{m}{2}\right\rfloor \\
0,1 \leq i \leq 2 ;\left\lfloor\frac{m}{2}\right\rfloor+1 \leq j \leq m-1
\end{array}\right. \\
& f\left(e^{\prime}{ }_{i, j}\right)=\left\{\begin{array}{l}
1, i=1 ; 1 \leq j \leq\left\lfloor\frac{m}{2}\right\rfloor \\
0, i=1 ;\left\lceil\frac{m}{2}\right\rfloor+1 \leq j \leq m-1 \\
1, i=2 ; j=\left\lfloor\frac{m}{2}\right\rfloor+1 \\
1, i=3 ; 1 \leq j \leq\left\lfloor\frac{m}{2}\right\rfloor \\
0, i=3 ;\left\lceil\frac{m}{2}\right\rfloor+1 \leq j \leq m-1
\end{array}\right.
\end{aligned}
$$

Berdasarkan fungsi tersebut diperoleh banyaknya sisi yang berlabel 0 adalah $e_{f}(0)=n-1$ dan banyaknya sisi yang berlabel 1 adalah $e_{f}(1)=n$. Sehingga $\left|e_{f}(0)-e_{f}(1)\right|=|(n-1)-n|=1$. Dengan demikian, fungsi pelabelan diatas adalah pelabelan prime cordial pada Graf Prisma $P_{(3, m)}$ dimana $m \geq 5$ ganjil. Jadi, graf prisma $P_{(3, m)}$ adalah graf prime cordial.

\section{Teorema 4 :}

Graf Prisma $P_{(5, m)}$ adalah prime cordialuntuk $n=5$ dan $m \geq 4$ genap

Bukti : Kasus $n=5$ dan $m \geq 4$ genap

Graf Prisma $P_{(5, m)}$ untuk $n=5$ dan $m \geq 4$ genap ditunjukan bahwa graf tersebut mempunyai pelabelan prime cordial dalam bentuk fungsi sebagai berikut : 


$$
f\left(v_{i, j}\right)=\left\{\begin{array}{l}
2 i-j ; 1 \leq i \leq n, j=1 \\
2 i ; 1 \leq i \leq n, j=\left\lceil\frac{m}{2}\right\rceil+1 \\
1+(j-1) 10 ; i=1,2 \leq j \leq\left\lfloor\frac{m}{2}\right\rceil \\
2+\left(j-1-\left\lceil\frac{m}{2}\right\rceil\right) 10 ; i=1, \quad\left\lceil\frac{m}{2}\right\rceil+2 \leq j \leq m \\
3+(j-1) 10 ; i=2,2 \leq j \leq\left\lfloor\frac{m}{2}\right\rceil \\
4+\left(j-1-\left\lceil\frac{m}{2}\right\rceil\right) 10 ; i=2, \quad\left\lceil\frac{m}{2}\right\rceil+2 \leq j \leq m \\
5+(j-1) 10 ; i=3,2 \leq j \leq\left\lfloor\frac{m}{2}\right\rfloor \\
6+\left(j-1-\left\lceil\frac{m}{2}\right\rceil\right) 10 ; i=3, \quad\left\lceil\frac{m}{2}\right\rceil+2 \leq j \leq m \\
7+(j-1) 10 ; i=4,2 \leq j \leq\left\lfloor\frac{m}{2}\right\rfloor \\
8+\left(j-1-\left\lceil\frac{m}{2}\right\rceil\right) 10 ; i=4, \quad\left\lceil\frac{m}{2}\right\rceil+2 \leq j \leq m \\
9+(j-1) 10 ; i=5,2 \leq j \leq\left\lfloor\frac{m}{2}\right\rfloor \\
10+\left(j-1-\left\lceil\frac{m}{2}\right\rceil\right) 10 ; i=5, \quad\left\lceil\frac{m}{2}\right\rceil+2 \leq j \leq m
\end{array}\right.
$$

dengan demikian diperoleh :

$$
\begin{aligned}
& f\left(e_{i, j}\right)=\left\{\begin{array}{l}
1,1 \leq i \leq 4 ; 1 \leq j \leq\left\lfloor\frac{m}{2}\right\rfloor \\
0,1 \leq i \leq 4 ;\left\lfloor\frac{m}{2}\right\rfloor+1 \leq j \leq m
\end{array}\right. \\
& f\left(e_{3, j}\right)=\left\{\begin{array}{l}
1,1 \leq i \leq 4 ; 1 \leq j \leq\left\lfloor\frac{m}{2}\right\rfloor \\
0,1 \leq i \leq 4 ;\left\lfloor\frac{m}{2}\right\rfloor+1 \leq j \leq m
\end{array}\right. \\
& f\left(e^{\prime}{ }_{i, j}\right)=\left\{\begin{array}{l}
1, i=1 ; 1 \leq j \leq\left\lfloor\frac{m}{2}\right\rfloor \\
0, i=1 ;\left\lceil\frac{m}{2}\right\rceil+1 \leq j \leq m \\
1, i=2 ; 1 \leq j \leq\left\lfloor\frac{m}{2}\right\rfloor \\
0, i=2 ;\left\lceil\frac{m}{2}\right\rceil+1 \leq j \leq m \\
0, i=3 ; 1 \leq j \leq m \\
1, i=4 ; 1 \leq j \leq\left\lfloor\frac{m}{2}\right\rfloor+1 \\
0, i=4 ;\left\lceil\frac{m}{2}\right\rceil+1 \leq j \leq m \\
1, i=5 ; 1 \leq j \leq\left\lfloor\frac{m}{2}\right\rfloor \\
0, i=5 ;\left\lceil\frac{m}{2}\right\rceil+1 \leq j \leq m
\end{array}\right.
\end{aligned}
$$

Berdasarkan fungsi tersebut diperoleh banyaknya sisi yang berlabel 0 adalah $e_{f}(0)=n-1$ dan banyaknya sisi yang berlabel 1 adalah $e_{f}(1)=n$. Sehingga $\left|e_{f}(0)-e_{f}(1)\right|=|(n-1)-n|=1$. Dengan demikian, fungsi pelabelan diatas adalah pelabelan prime cordial pada Graf Prisma $P_{(5, m)}$ untuk $m \geq 4$ genap. Jadi, graf prisma $P_{(5, m)}$ adalah graf prime cordial. 


\subsection{PEMBAHASAN}

Berdasarkan hasil diatas dinyatakan bahwa graf prisma $P_{(3, m)}$ untuk $m \geq 5$ ganjil dan $P_{(5, m)}$ untuk $m \geq 4$ genap adalah graf prime cordial. Disamping itu, dapat ditunjukan pula bahwa graf terhubung antar pusat pada graf roda $W_{n, t}$ dengan $t \in\{2,4,6\}$ dengan $m \geq 3$ adalah graf prime cordial. Namun secara umum, untuk graf $W_{n, t}$ dengan $t \geq 6$ dan $n \geq 3$ belum dapat dibuktikan sifat prime cordialnya. Demikian juga untuk graf $P_{(n, m)}$ dengan $n \geq 5$ dan $m \geq 3$. Untuk itu, kasus ini masih menjadi masalah terbuka yang sangat menarik untuk dibuktikan bila ada yang berminat untuk meneliti dibidang ini.

\section{KESIMPULAN}

Berdasarkan hasil penelitian yang telah dilakukan, dapat disimpulkan bahwa :

1. Graf terhubung antar pusat pada graf roda $W_{n, t}$ untuk setiap $n \geq 3$ dan $t=2$ adalah pelabelan prime cordial.

2. Graf terhubung antar pusat pada graf roda $W_{n, t}$ untuk setiap $n \geq 3$ dan $t=4$ adalah pelabelan prime cordial.

3. Graf terhubung antar pusat pada graf roda $W_{n, t}$ untuk setiap $n \geq 3$ dan $t=6$ adalah pelabelan prime cordial.

4. Graf prisma $P_{n, m}=C_{n} \times P_{m}$ untuk setiap $n=3$ dan $m \geq 5$ ganjil adalah prime cordial.

5. Graf prisma $P_{n, m}=C_{n} \times P_{m}$ untuk setiap $n=5$ dan $m \geq 4$ genap adalah prime cordial.

\section{DAFTAR PUSTAKA}

[1] Cunningham, D. 2004. "Vertex magic". The Electronic journal of undergraduate Mathematics, Vol. 9, 1-20.

[2] Dubrov, B. 2000. Some Application of Graph in Chemistryl. (http://Pubs.acs.org ), tanggal akses : 5 Desember 2014 pukul 20.00.

[3] Erisia, Y. R. 2011. Pelabelan Prim untuk Beberapa Graf Hasil Operasi dari Graf Sikel, Universitas Diponegoro. Semarang.

[4] Kusumawardana, M. 2009. Aplikasi Teori Graf pada Analisis Jejaring sosial. ITB. Bandung.

[5] Munir, R. 2003. Matematika Diskrit. Informatika Bandung. Bandung.

[6] Susmikanti, M. 2006. Komputasi Komputer Terhubung dan Jalur Terpendek dalam Algoritma Paralel. Pusat Pengembangan Informatika Teknologo Nuklir. BATAN. 